\title{
Prevention of infection in asplenic adult patients by general practitioners in France between 2013 and 2016
}

\section{Care for the asplenic patient in general practice}

\author{
Charlotte Quéffélec ${ }^{1}$, Louis Billet ${ }^{2}$, Pierre Duffau ${ }^{3,4}$, Estibaliz Lazaro ${ }^{1,4}$, Irène Machelart ${ }^{1}$, Carine Greib ${ }^{1}$, \\ Jean-François Viallard ${ }^{1,5}$, Jean-Luc Pellegrin ${ }^{1,4}$ and Etienne Rivière ${ }^{1,5^{*}}$
}

\begin{abstract}
Background: Guidelines that detail preventive measures against Streptococcus pneumoniae, Neisseria meningitidis, Haemophilus influenzae type $b$, and influenza are published annually in France to decrease the risk of severe infections in immunocompromised patients. We aimed at describing adherence to these guidelines by GPs in the management of their asplenic patients in France between 2013 and 2016.

Method: We conducted a multicenter retrospective study between January 2013 and December 2016 in three French hospitals: asplenic adults were identified and their GPs were questioned. A descriptive analysis was performed to identify the immunization coverage, type and length of antibiotic prophylaxis, number of infectious episodes, and education of patients.

Results: 103 patients were finally included in this study: only 57\% were adequately vaccinated against Streptococcus pneumoniae or Neisseria meningitidis, 74\% against Haemophilus influenzae type b, and 59\% against influenza. Only $24 \%$ of patients received a combination of all four vaccinations. Two-thirds of patients received prophylactic antibiotics for at least 2 years. Overall, this study found that $50 \%$ of splenectomized patients experienced at least one pulmonary or otorhinolaryngological infection, or contracted influenza.

Conclusions: These data match those reported in other countries, including Australia and the United Kingdom, meaning a still insufficient coverage of preventive measures in asplenic patients. Improved medical data sharing strategies between healthcare professionals, along with educational measures to keep patients and physicians up to date in the prevention of infections after splenectomy would improve health outcomes of asplenic patients.
\end{abstract}

Keywords: Splenectomy, General practice, Infections, Vaccination

\footnotetext{
* Correspondence: e.riviere@neuf.fr

'Internal Medicine and Infectious Diseases Unit, Haut-Leveque Hospital,

University Hospital Centre of Bordeaux, F33600 Pessac, France

5INSERM U1034, Bordeaux University, F33604 Pessac Cedex, France

Full list of author information is available at the end of the article
}

(c) The Author(s). 2020 Open Access This article is licensed under a Creative Commons Attribution 4.0 International License, which permits use, sharing, adaptation, distribution and reproduction in any medium or format, as long as you give appropriate credit to the original author(s) and the source, provide a link to the Creative Commons licence, and indicate if changes were made. The images or other third party material in this article are included in the article's Creative Commons licence, unless indicated otherwise in a credit line to the material. If material is not included in the article's Creative Commons licence and your intended use is not permitted by statutory regulation or exceeds the permitted use, you will need to obtain permission directly from the copyright holder. To view a copy of this licence, visit http://creativecommons.org/licenses/by/4.0/ The Creative Commons Public Domain Dedication waiver (http://creativecommons.org/publicdomain/zero/1.0/) applies to the data made available in this article, unless otherwise stated in a credit line to the data. 


\section{Background}

In France, approximately 9000 patients underwent a splenectomy in 2016 due to trauma, lymphoid or myeloid neoplasm, autoimmune cytopenia, or in search of a diagnosis [1]. In addition to an increased thrombotic risk, asplenic patients also have a high risk of developing severe infections due to the roles of the spleen in blood filtration and in adaptive immunity. The most serious type of infection, caused by encapsulated bacteria, has a mortality rate of $50 \%$ within $48 \mathrm{~h}$ and is known as overwhelming postsplenectomy infection (OPSI) $[2,3]$. Due to the presence of a specialized population of B lymphocytes in the splenic marginal zone that produce IgMs specific for the TI-2 protein of the polysaccharide capsule of OPSI causing bacteria, the spleen has the ability to eliminate these opsonization-resistant pathogens $[3,4]$.

Although the infectious risk in asplenic patients is high during their entire life, it is highest during the first 2 years following splenectomy and decreases over time. Therefore, national [5] and international guidelines [69] are regularly published to limit this infectious risk in asplenic patients by regularly up-dating the vaccination or antibiotic prophylaxis. For pneumococcal vaccination, the prime-boost strategy combines a 13-valent conjugate vaccine (pneumococcal conjugate vaccine-13, or "PCV13") with a 23-valent-polysaccharide vaccine (pneumococcal polysaccharide vaccine-23, or "PPSV23") 2 months after, then once every 5 years. In case of emergent splenectomy, PCV13 should be administered as soon as possible after surgery (ideally 15 days after, but sooner if the patient is at risk to be lost to follow-up), with PPSV23 2 months later. Vaccination against the main serogroups of Neisseria meningitidis, ACWY and $\mathrm{B}$, comprises two injections either 6 months (for ACWY) or 1 month (for B) apart, with a recall against ACWY serogroups every 5 years. In addition, one injection of the Haemophilus influenzae type b (HIB) vaccine and one injection every year of the seasonal influenza vaccine are recommended. Furthermore, long-term prophylactic oral daily administration of an antibiotic, mainly phenoxymethylpenicillin, is required for at least 2 years after splenectomy to cover the period during which the infectious risk is highest [6-9]. General practitioners (GPs) have a central role in applying these preventive measures in collaboration with other physicians caring for the patient (oncologists, haematologists, internists, surgeons etc.). However, the institution of these preventive measures in asplenic patients appears insufficient, and there is also very heterogeneous post hoc management of infectious events [10-12]. Since the role of GPs is crucial in preventive and curative measures, we aimed to analyze the management of asplenic patients by GPs in accordance with published guidelines in France between the years of 2013 and 2016.

\section{Methods}

A retrospective study was carried out in three French hospitals located in Bordeaux, Bayonne, and Pau, whose number of beds and chairs are respectively 3067, 1224 and 838. Adult patients (age $\geq 18$ ) who underwent a splenectomy during the time period encompassing January 2013 to December 2016 were identified using the database in the three participating hospitals. Patients' GPs were therefore questioned about the management of their asplenic patients, and this data collection was conducted between December 2017 and June 2018. GPs' names were recorded in patients' medical files. GPs were administered a questionnaire by phone to gather details about vaccinations against Streptococcus pneumonia, Neisseria meningitidis, HIB, and influenza virus, and prescription of prophylactic antibiotics, management of infectious events (mainly laboratory confirmed), patient's possession of an emergency card, and information delivered to the patients. This questionnaire is available as Supplemental file 1. In our study, no GP took care of more than one asplenic patient, and all were aware of the splenectomy performed in their patient.

Exclusion criteria were established to exclude the following groups of asplenic patients: 1) non-adult patients, 2) patients who died of any cause between their splenectomy and the onset of data collection, 3) patients with partial splenectomy, 4) patients with functional asplenism, 5) patients without a GP, 6) patients whose GPs refused to participate or did not respond; 7) patients who had changed GPs, and 8) patients lost to follow-up. Medical records of included asplenic patients were utilized to gather information about prophylactic measures initiated before and after splenectomy by specialists other than the patients' GPs, as well as any postoperative complications.

The questionnaire was registered at the National Commission on Informatics and Liberty (CNIL) in France (\#MR-00313810*01, December 2017) and scrutinized for validation and confidentiality of collected data; our institutional review board also approved research. A descriptive analysis was then performed to identify the immunization coverage and the type and length of antibiotic prophylaxis. A univariate analysis assessed the effect of the cause underlying the splenectomy on the administered preventive measures. Chi-squared and Fisher's exact test were used to statistically interrogate the collected data. All statistical analyses were performed with RStudio $^{\circ}$ software, with statistical significance defined as $p<0.05$.

\section{Results}

We found that at the three chosen hospitals, $266 \mathrm{pa}-$ tients were splenectomized between January 2013 and December 2016. Among these patients, 163 were 
excluded based on the criteria stated in the Methods section and summarized in Fig. 1. For the remaining 103 patients, we gathered data on the general characteristics, cause of the splenectomy and duration of follow-up by GPs in the medical files (Table 1). Then, patients were divided into 4 groups based on the precipitating cause for their splenectomy: 1) trauma and iatrogenesis, 2) malignancy, 3) autoimmune cytopenia, and 4) other (Table S1). Trauma and idiopathic thrombocytopenic purpura were the most common causes of splenectomy $(n=44)$. We then called patients' GPs to gather additional information about their care to their asplenic patient during a mean follow-up period of 3.5 years (Table 1 ).

First, we analyzed preventive measures. Importantly, only $24 \%$ adequately received all recommended vaccinations combined (Table 2). Overall, 87\% received at least one injection of a pneumococcal vaccine, and 57\% received the necessary pneumococcal vaccination booster. Since boosted vaccination against Streptococcus pneumoniae was introduced in the 2014 guidelines in France, we noted that $76 \%$ of splenectomized patients in 2016 received the boosted pneumococcal vaccination compared to $52 \%$ in $2013(p=0.0005)$. Univariate analysis revealed that patients with autoimmune cytopenia were significantly more vaccinated against Streptococcus pneumoniae compared to the other three groups $(p=0.038$, Table S2). Vaccination rates against other germs are summarized in Table 2.

Antibiotic prophylaxis was administered in 68 of 103 patients (66\%). However, prescription duration was heterogeneous as shown in Fig. 2. GPs reported that the absence of antibiotic prophylaxis and a short prescription duration of under 2 years in 45 patients were both linked to oversight or unfamiliarity with established guidelines. Long-term prescriptions of over 2 years were either given by specialized physicians for patients with haematological malignancies or solid neoplasms $(n=8)$, or due to the unawareness of physicians that established guidelines limited prescription duration to 2 years $(n=11)$. Three patients had an allergic reaction to the prescribed antibiotic, so drug administration was stopped without prescription of a new antibiotic. Oral penicillin $\mathrm{V}$ was used in 62 patients while 6 patients received another antibiotic (amoxicillin in 4 patients, and erythromycin in 2 patients).

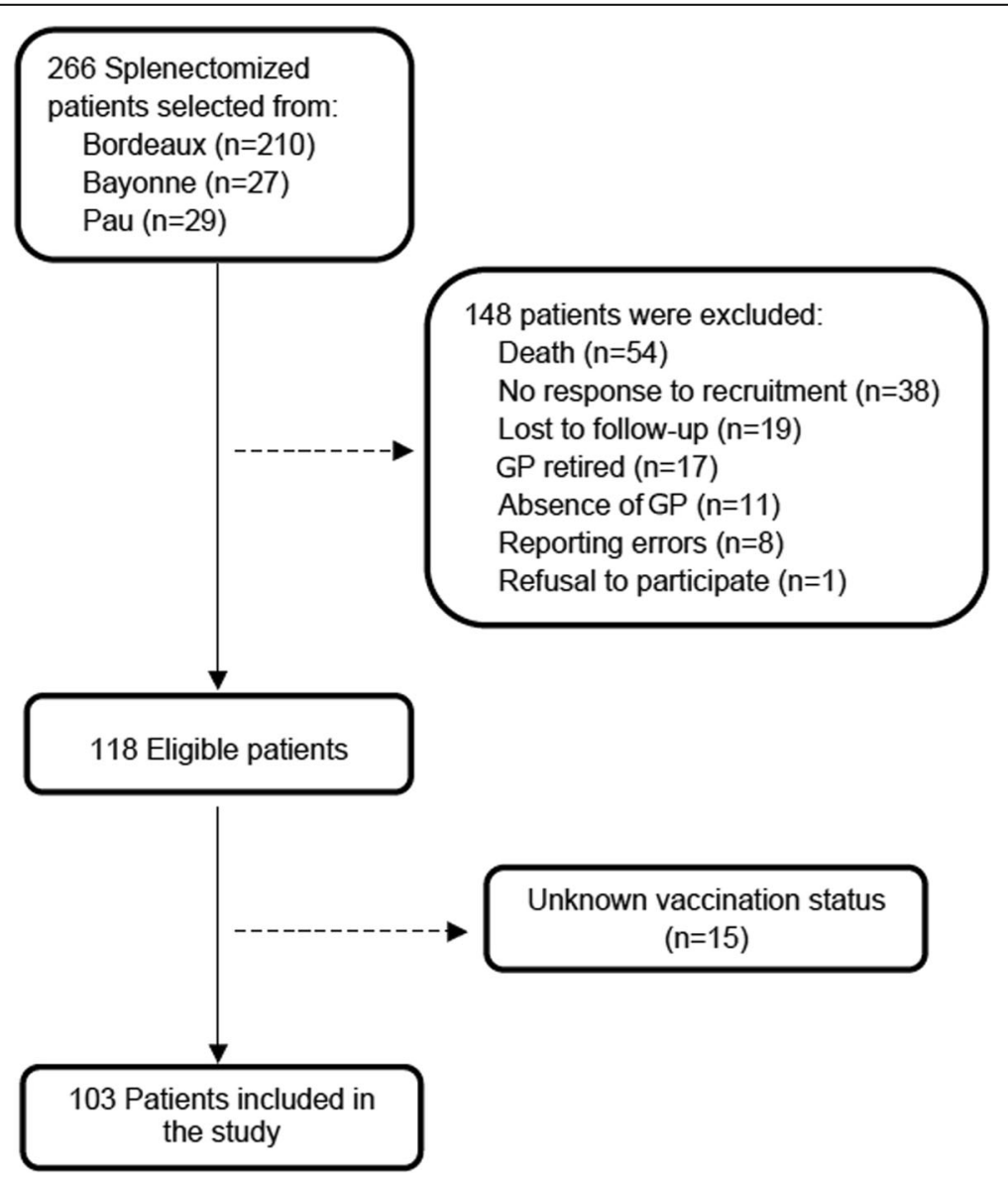

Fig. 1 Flow Chart of the Study Population 
Table 1 Patient Characteristics

\begin{tabular}{ll}
\hline & Number of patients \\
\hline Gender & 52 \\
Male & 51 \\
Female & \\
Age, years & 57 (20-84) \\
Median (range) & 55 \\
Mean & \\
Cause of splenectomy & 31 \\
Trauma and iatrogenesis & 28 \\
Malignancy & 23 \\
Autoimmune cytopenia ${ }^{a}$ & 21 \\
Other & \\
Follow-up time, years & 25 \\
$<2$ & 23 \\
$2-3$ & 34 \\
$3-4$ & 21 \\
$>4$ & 3.5 \\
Mean &
\end{tabular}

${ }^{a}$ Autoimmune cytopenias were idiopathic thrombocytopenic purpura (ITP) and autoimmune haemolytic anaemia (AlHA)

Next, we detailed infectious episodes reported by GPs between 2013 and 2016. Of note, 47 patients (45\%) developed at least one infection: 24 (23\%) had one infectious episode, 12 (11\%) two, 2 (2\%) three, and $9(8 \%)$ more than three; 56 patients had no infectious episode. The majority of these were pulmonary or ear-nose and throat infections, isolated fevers, or flu (Table S3). Notably, 4 patients who had not been previously vaccinated or receiving antibiotic prophylaxis had an overt OPSI in the month following splenectomy. Of these, 3 patients had reversible respiratory failure and one patient had urinary and intra-abdominal infections with bacteraemia and septic shock. Two other patients were tested positive for additional pathogens including Escherichia coli, Pseudomonas aeruginosa, Enterobacter cloacae, and methicillin-resistant Staphylococcus aureus while under postoperative care. In addition to these 6 patients, 7 others had to be hospitalized to manage an infection; however, a complete diagnostic assessment was only carried out in $28 \%$ of all infectious cases.

Then, we analyzed the main infections in the 31 asplenic patients who received vaccinations. The number of infectious episodes due to pathogens potentially covered by the vaccines (pulmonary, otorhinolaryngological, and influenza infections due to Streptococcus pneumoniae, Haemophilus type B, or influenza virus) are shown in Table 3. Of note, these patients were very heterogeneously vaccinated, and half were receiving antibiotic prophylaxis. In addition, these infectious episodes were present in different proportions of patients according to the cause of splenectomy with the following distribution: 9.7\% with autoimmune cytopenias, $22.6 \%$ with trauma and iatrogenesis, $29 \%$ with malignancy, and $38.7 \%$ with other causes. Thus, the data in our study suggest that patients with autoimmune cytopenia had fewer episodes of pulmonary, ear nose throat, and influenza infections. On the other hand, patients with malignancies had more infectious episodes. Specifically, six out of 9 patients experiencing more than

Table 2 Patient Vaccination Details

\begin{tabular}{|c|c|c|}
\hline Strains & Vaccinated & Not vaccinated \\
\hline Pneumococcal & $n=90(87.38 \%)$ & $n=13(12.62 \%)$ \\
\hline Adequate PCV13/PPSV23 vaccination schedule & $n=59(57.28 \%)$ & \\
\hline Inadequate PCV13/PPSV23 vaccination schedule & $n=5(4.85 \%)$ & \\
\hline PCV13 only & $n=6(5.83 \%)$ & \\
\hline PPSV23 only & $n=20(19.42 \%)$ & \\
\hline Meningococcus (by serogroups) & $n=59(57.28 \%)$ & $n=44(42.72 \%)$ \\
\hline C & $n=24(23.30 \%)$ & \\
\hline$A C$ & $n=10(9.70 \%)$ & \\
\hline ACWY & $n=20(19.42 \%)$ & \\
\hline B & $n=1(0.98 \%)$ & \\
\hline$C+B$ & $n=2(1.94 \%)$ & \\
\hline$A C W Y+B$ & $n=2(1.94 \%)$ & \\
\hline Haemophilus influenzae B & $n=77(74.76 \%)$ & $n=26(25.24 \%)$ \\
\hline Annual Influenza & $n=61(59.22 \%)$ & $n=42(40.78 \%)$ \\
\hline All vaccinations, ie adequate PCV13/PPSV23 $+A C W Y / B+H I B+$ influenza vaccination schedules & $n=24(23.30 \%)$ & $n=79(76.70 \%)$ \\
\hline
\end{tabular}




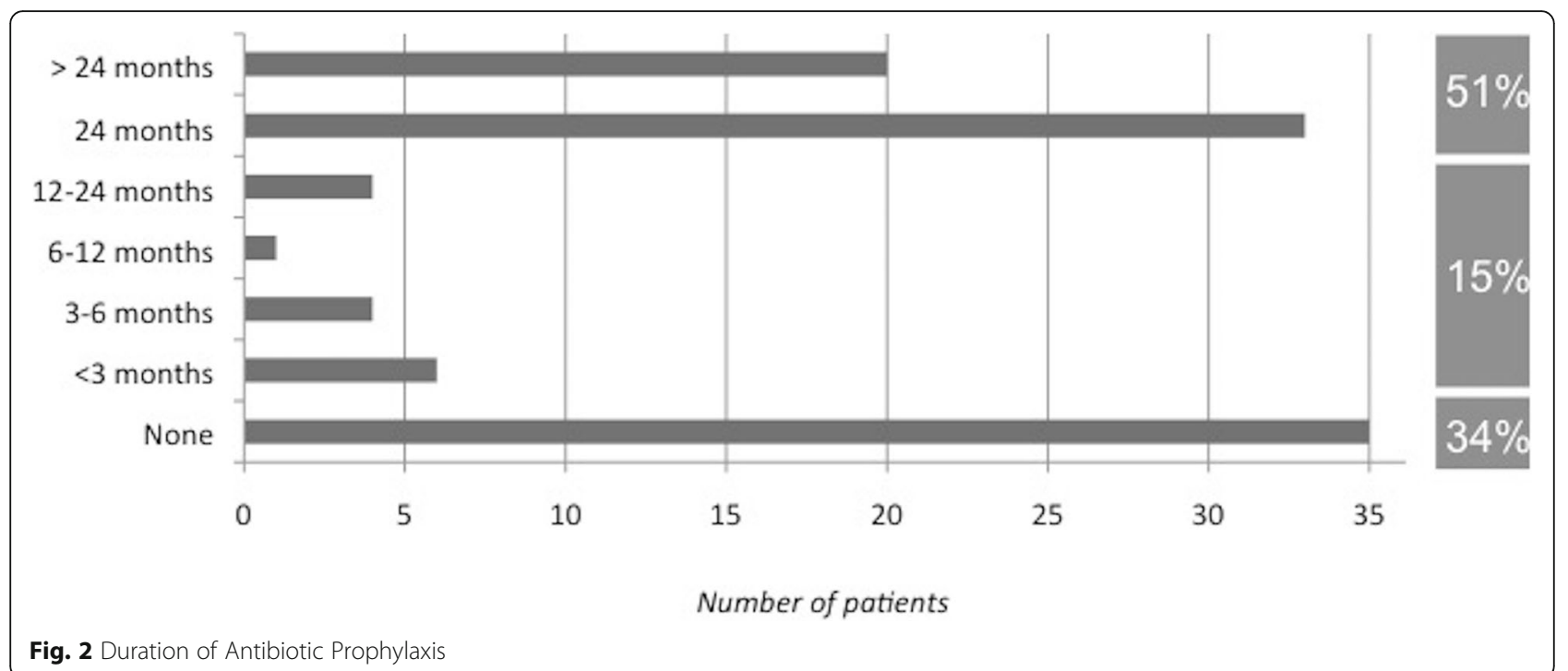

3 infectious episodes had lymphoma. No patients had meningococcal infection.

Finally, we assessed how patients were informed about their increased risk for infection. Patients only received oral information about the global risks of the splenectomy, and in $74 \%$ of cases, this information was delivered by hospital physicians. As indicated by GPs, we found that 16 patients had an emergency alert card without knowing its precise origin or type.

\section{Discussion}

Our results show that asplenic patients are not adequately protected against the common pathogens that are targeted by vaccination and antibiotic prophylaxis in clinical practice: only $24 \%$ of patients received all recommended vaccines and $66 \%$ received adequate antibiotic prophylaxis.

Of note, the rate of flu vaccination was probably underestimated by GPs since nurses are authorized to independently vaccinate against influenza in France since 2008.
We confirm in our study that the risk of infection remains high in asplenic patients, even in patients receiving prophylactic antibiotics, especially in case of haematological disease, neoplasm, or older age [13, 14]. We identified 83 infectious events, mainly pulmonary or ENT infections and influenza, reported by GPs in 47 patients. This is likely an underestimation since patients could have potentially consulted another healthcare professional, such as physicians in emergency units. Lastly, we identified 4 occurrences of OPSI in the month following splenectomy in patients who did not receive any vaccine or antibiotic prophylaxis.

Recent work in other regions of France and Australia also showed a low pneumococcal vaccination rate of 18.8 and $7 \%$, respectively $[10,15]$. Similar to our study, international studies have reported a pneumococcal vaccination rate between 60 and 88\% [10,12, 16-23]. Our study shows, however, that only $57 \%$ of patients received the adequate booster. An increased rate of boosted antipneumococcal vaccination was observed only in medical records from 2016, despite the published recommendation

Table 3 Infections Due to Bacteria with Potential Coverage by Vaccines or Antibiotic Prophylaxis

\begin{tabular}{|c|c|c|c|c|c|c|c|}
\hline \multirow{2}{*}{$\begin{array}{l}\overrightarrow{\text { Preventive ongoing }} \\
\text { measures } \\
\rightarrow\end{array}$} & \multicolumn{3}{|c|}{ In asplenic patients vaccinated with pneumococcal vaccines } & \multirow{2}{*}{$\begin{array}{l}\text { In asplenic } \\
\text { patients } \\
\text { vaccinated } \\
\text { with HIB } \\
\text { vaccine }\end{array}$} & \multirow[b]{2}{*}{$\begin{array}{l}\text { In asplenic } \\
\text { patients } \\
\text { vaccinated } \\
\text { with } \\
\text { annual } \\
\text { influenza } \\
\text { vaccine }\end{array}$} & \multirow[b]{2}{*}{$\begin{array}{l}\text { In asplenic } \\
\text { patients } \\
\text { vaccinated } \\
\text { with } \\
\text { Neisseria } \\
\text { meningitidis } \\
\text { vaccines } \\
\text { (all } \\
\text { serogroups) }\end{array}$} & \multirow[b]{2}{*}{$\begin{array}{l}\text { In asplenic } \\
\text { patients } \\
\text { receiving } \\
\text { antibiotic } \\
\text { prophylaxis } \\
\geq 2 \text { years }\end{array}$} \\
\hline & with PCV13 only & with PPSV23 only & with PCV13+PPSV23 & & & & \\
\hline $\begin{array}{l}\text { Number of infections (lung } \\
\text { and/or ENT } \\
\text { and/or influenza) } \\
(N=31)\end{array}$ & 2 & 9 & 16 & 22 & 21 & 14 & 18 \\
\hline
\end{tabular}


for a booster schedule in 2014 in France. This indicates a notable delay in implementation by physicians. Of note, patients with autoimmune cytopenias had the most number of vaccinations against Streptococcus pneumoniae compared to the other groups, likely because these patients were more frequently vaccinated prior to the administration of necessary immunosuppressive agents to combat their autoimmune disorder [24].

Regarding vaccination against Neisseria meningitides, the vaccination rate was higher in our study than in other previously published results $[10,23,25]$, as was the rate of vaccination against $\operatorname{HIB}[10,16,18,22,23$, 25]. Of note, the low vaccination rate against $B$ serogroup can be partly explained by the evolution of guidelines in France, as the anti-MenB vaccine was recommended for asplenic patients in 2013 and reimbursed by the Sécurite Sociale in December 2014. However the vaccination rate against MenB still remains low. Finally, the proportion of asplenic patients receiving antibiotic prophylaxis is slightly lower than previously reported $[10,13,26,27]$.

Our study describes the medical management of asplenic patients by GPs, adding valuable insights to an otherwise scarce body of work. The total number of patients analysed exceeds other similar international studies. Nevertheless, our study has several limitations. Of note, the data from 166 patients could not be analyzed, mostly because their were deceased, lost to follow-up, or because their GP did not answer to our solicitations or had retired at the time of the study. We also identified four biases inherent to the chosen methodology of research: 1) a non-response bias due to GPs who did not want to participate, 2) selective survival bias linked to the presence of many deceased asplenic patients within the chosen timeframe, 3) recall bias, especially for collecting information about patients' education through GPs, and 4) storage bias. In addition, the questionnaire was not designed to assess patients' compliance with the prescribed schedule/dosage of antibiotic prophylaxis, timing of vaccination in patients receiving immunosuppressive therapies, effective therapeutic education of the patient, patients' general knowledge regarding asplenic states, or availability of a curative antibiotic without a prescription. Finally, timing of this study has not indexed PPSV23 recall at 5 years.

\section{Implications for research and/or practice} How to increase the infectious prophylaxis in asplenic patients in general practice?

A dedicated healthcare network has been reported useful for the follow-up of asplenic patients in several countries [21, 28-32]. Moreover, creating nationwide registries of asplenic patients has correlated with improved implementation of established guidelines among physicians and allowed for the dissemination of useful information, medical advice, and vaccination reminder in a cost-effective manner [15, 26, 33]. We insist on the central role of hospital specialists taking care of the patient before and at the time of splenectomy for starting the preventive measures against infection, and beginning patient's medical education about his future asplenic state. Furthermore, the ongoing implementation of a shared medical record system in France will certainly be useful to synchronize asplenic patients care in the future. Finally, GPs are crucial to coordinate care for patients with chronic blood diseases starting an infectious episode, in cooperation with hematologists. Helpful measures for physicians to improve care of the asplenic patient are summarized in Table 4.

It is important to note that, despite good vaccination coverage, asplenic patients remain at risk for infection, notably those not covered by vaccines such as enteritis or cold. However, adequate vaccination against encapsulated bacteria will limit the risk of severe infectious complications.

\section{How to improve patient education before and after splenectomy?}

Despite the advent of vaccination and antibiotic prophylaxis, ongoing guidelines are not adequately implemented in clinical practice. Our study shows that patients are not well enough informed regarding the infectious risk associated with their asplenic state $[16,36-38]$ while it has been shown that patient's education can reduce the risk of OPSI [37]. Our data suggest that improved communication between healthcare professionals can decrease the incidence of infection in these patients. In fact, $13 \%$ of patients were excluded from our study because their GPs were unaware or uncertain about the patients' antiinfectious prophylactic measures. In addition, the majority of patients only received information orally from their physicians, but no written documents. In healthcare education, audiovisual support and printed documents have been shown to be more effective in strengthening medical education and the understanding of patients compared to oral information [16, 39, 40]. To that end, previous studies analyzed the tools and quality of written information available on the internet for asplenic patients to assess the quality of accessible information [41, 42]. These studies found that countries such as Australia [43] and United Kingdom [44] provide dedicated websites to asplenic patients in addition to information leaflets and patient emergency cards. It is clear that standardization of educational material regarding asplenic states is needed in other countries. 
Table 4 Measures to Improve Care of Asplenic Patients in Healthcare Practice (adapted from [3, 6-8, 34, 35])

Vaccinate against commonly encountered encapsulated bacteria and influenza

(guidelines may vary according to each country)
Antibiotic prophylaxis

Therapeutic education

\author{
Streptococcus pneumoniae \\ PCV13 then PPSV23 2 to 12 months later (boosted strategy) \\ - consider another boosted strategy if PPSV23 has been injected \\ more than one year after PCV13 \\ - consider adding PCV13 if PPSV23 was given first, and do a new \\ boosted vaccination 5 years after the PPSV23 injection \\ - respect a 5-year minimum interval between two doses of PPSV23
}

\section{Neisseria meningitidis}

Consider two doses of tetravalent ACWY vaccine in a 6-month interval, and a recall every 5 years

Consider two doses of anti-MenB vaccine in a 1-month interval

\section{Haemophilus influenzae type $b$}

Consider one dose of the vaccine in adulthood

\section{Influenzae}

Consider an annual dose of vaccine in November

Oral penicillin V, or erythromycin in case of allergy, for at least two years

- consider lifelong prophylaxis in patients at high risk: age $<16$ or $>50$, survival to a first OPSI episode, patients with haematological diseases, HIV, or ongoing immunosuppressive therapies, or inadequate response to pneumococcal vaccination

- reconsider this attitude regarding the evolution of local bacterial ecology and patient's medical history or concomitant medications over time (drug interactions or contra-indications)

\section{Educate patients with recurrent information about:}

- the function of the spleen

- the infectious risk: encapsulated bacteria, the role of influenza in such infections, alert signs of infection, how to act at signs of infection

- vaccinations to be done over time

- antibiotic prophylaxis

- animal and tick bites

- communication of the asplenic state to other healthcare professionals

- medical ID (splenectomy card or personalized medical ID)

- travel advice

\section{Conclusions}

Our study shows that asplenic patients are insufficiently protected against encapsulated bacteria. The role of GPs is central in long-term monitoring and management of infectious events in this population of patients, in collaboration with all healthcare professionals. Guideline implementation must be improved through adequate transmission of information between healthcare professionals, and iterative and complete education of both physicians and asplenic patients.

\section{Supplementary information}

Supplementary information accompanies this paper at https://doi.org/10. 1186/s12875-020-01237-3.

Additional file 1. 7-question questionnaire used by main investigator (CQ) to question GPs about their management of their asplenic patient.

Additional file 2: Supplemental Table 1. Detailed Indications for Splenectomy in the Study Population.

Additional file 3: Supplemental Table 2. Univariate Analysis of the Vaccinations Received According to the Cause of Splenectomy.

Additional file 4: Supplemental Table 3. Notification of Infections by GPS.

\section{Abbreviations}

GP: General practitioner; OPSI: Overwhelming post-splenectomy infection; PCV-13: Pneumococcal conjugate vaccine-13; PPSV23: Pneumococcal polysaccharide vaccine-23; HIB: Haemophilus influenzae type B; CNIL: National Commission on Informatics and Liberty; ENT: Ear-nose-throat

\section{Acknowledgements}

The authors acknowledge the assistance of JetPub Scientific

Communications LLC, in the preparation of this manuscript, in accordance with Good Publication Practice (GPP3) guidelines.

\section{Authors' contributions}

CQ was responsible for investigation, formal analysis, data curation, writing original draft, and visualization; LB for methodology, software, formal analysis, and data curation; PD, EL, IM, CG \& JFV were responsible for data curation, validation, writing - review \& editing; JLP was responsible for validation and supervision; and ER was responsible for conceptualization, methodology, writing - original draft, writing - review \& editing, supervision, and project administration. The author(s) read and approved the final manuscript.

Funding

None.

\section{Availability of data and materials}

The datasets used and/or analysed during the current study available from the corresponding author on reasonable request.

Ethics approval and consent to participate

The questionnaire was registered at the National Commission on Informatics and Liberty (CNIL) in France (\#MR-003 13810*01, December 2017) and 
scrutinized for validation and confidentiality of collected data; our institutional review board also approved research. Written and verbal informed consents were obtained from GPs before and during the conversations, all participating GPS agreed to the present research.

\section{Consent for publication}

Not applicable.

\section{Competing interests}

None.

\section{Author details}

${ }^{1}$ Internal Medicine and Infectious Diseases Unit, Haut-Leveque Hospital, University Hospital Centre of Bordeaux, F33600 Pessac, France. ${ }^{2}$ Medical Information Department, Pellegrin Hospital, University Hospital Centre of Bordeaux, F33076 Bordeaux, France. ${ }^{3}$ Internal Medicine and Clinical Immunology Unit, Saint-André Hospital, University Hospital Centre of Bordeaux, F33000 Bordeaux, France. ${ }^{4}$ UMR CNRS 5164, ImmunoConcEpT \& FHU ACRONIM, Bordeaux University, F33000 Bordeaux, France. ${ }^{5}$ INSERM U1034, Bordeaux University, F33604 Pessac Cedex, France.

\section{Received: 17 April 2020 Accepted: 29 July 2020}

\section{Published online: 12 August 2020}

\section{References}

1. Coignard-Biehler H. Infections chez le splénectomisé. Rev Prat Médecine Générale. 2016;30:363-5.

2. Buzelé $R$, Barbier $L$, Sauvanet $A$, et al. Medical complications following splenectomy. J Visc Surg. 2016;153:277-86.

3. Di Sabatino A, Carsetti R, Corazza GR. Post-splenectomy and hyposplenic states. Lancet Lond Engl. 2011;378:86-97.

4. Bronte $\mathrm{V}$, Pittet $\mathrm{M}$. The spleen in local and systemic regulation of immunity. Immunity. 2013:39:806-18.

5. HCSP. Vaccination des personnes immunodéprimées ou aspléniques. Recommandations actualisées. Paris: Haut Conseil de la Santé Publique. 2014. https://www.hcsp.fr/explore.cgi/avisrapportsdomaine? clefr $=504$. Accessed 18 Aug 2019

6. Rubin LG, Schaffner W. Clinical practice. Care of the asplenic patient. N Engl J Med. 2014:371:349-56.

7. Kroger AT, Duchin J, Vázquez M. General Best Practice Guidelines for Immunization. Best Practices Guidance of the Advisory Committee on Immunization Practices (ACIP). https://www.cdc.gov/vaccines/hcp/acip-recs/ general-recs/index.html, https://www.cdc.gov/vaccines/hcp/acip-recs/ general-recs/index.html. Accessed 10 Jan 2019.

8. Davies JM, Lewis MPN, Wimperis J, et al. Review of guidelines for the prevention and treatment of infection in patients with an absent or dysfunctional spleen: prepared on behalf of the British Committee for Standards in Haematology by a working party of the Haemato-oncology task force. Br J Haematol. 2011;155:308-17.

9. Kanhutu $K_{\text {, Jones }}$, Cheng AC, et al. Spleen Australia guidelines for the prevention of sepsis in patients with asplenia and hyposplenism in Australia and New Zealand. Intern Med J. 2017:47:848-55.

10. Coignard-Biehler $\mathrm{H}$, Lanternier $\mathrm{F}$, Hot $\mathrm{A}$, et al. Adherence to preventive measures after splenectomy in the hospital setting and in the community. J Infect Public Health. 2011:4:187-94.

11. Lammers AJJ, van der Maas NAT, Peters EJG, et al. Prevention of severe infections in patients with hyposplenism or asplenia. Ned Tijdschr Geneeskd. 2012;156:A4857.

12. O'Donnell J, McGreal G, Daly P, et al. Management of patients undergoing splenectomy in an Irish teaching hospital: impact of guidelines. Ir J Med Sci. 2004;173:136-40.

13. Meriglier $E$, Puyade $M$, Carretier $M$, et al. Long-term infectious risks after splenectomy: a retrospective cohort study with up to 10 years follow-up. Rev Med Interne. 2017:38:436-43.

14. Edgren $G$, Almqvist $R$, Hartman $M$, et al. Splenectomy and the risk of sepsis: a population-based cohort study. Ann Surg. 2014;260:1081-7.

15. Luu S, Dendle $C$, Jones $P$, et al. Impact of a spleen registry on optimal postsplenectomy vaccination and care. Hum Vaccines Immunother. 2018;14 2894-9

16. Kealey GP, Dhungel V, Wideroff MJ, et al. Patient education and recall regarding postsplenectomy immunizations. J Surg Res. 2015;199:580-5.
17. Bruni L, Bayas JM, Vilella A, et al. Vaccination coverage in adults undergoing splenectomy: evaluation of hospital vaccination policies. Epidemiol Infect. 2006;134:837-44.

18. Kyaw $\mathrm{MH}$, Holmes EM, Toolis $\mathrm{F}$, et al. Evaluation of severe infection and survival after splenectomy. Am J Med. 2006;119:276.e1-7.

19. Hasse B, Moll C, Oehy K, et al. Anti-infectious prophylaxis after splenectomy: current practice in an eastern region of Switzerland. Swiss Med Wkly. 2005; 135:291-6.

20. Kotsanas D, Al-Souffi MH, Waxman BP, et al. Adherence to guidelines for prevention of postsplenectomy sepsis. Age and sex are risk factors: a fiveyear retrospective review. ANZ J Surg. 2006;76:542-7.

21. McHugh SM, O'Donnell J, Leahy A, et al. Transforming management of patients undergoing splenectomy in an Irish teaching hospital. Ir J Med Sci. 2011;180:655-9.

22. Lammers J. The value of prophylactic vaccinations and antibiotic treatment in post-splenectomy patients: a review. Transpl Res Risk Manag. 2012;4:1924.

23. Nived $P$, Jørgensen CS, Settergren B. Vaccination status and immune response to 13-valent pneumococcal conjugate vaccine in asplenic individuals. Vaccine. 2015;33:1688-94.

24. Moulis G, Lapeyre-Mestre M, Palmaro A, et al. Infections in non-splenectomized persistent or chronic primary immune thrombocytopenia adults: risk factors and vaccination effect. J Thromb Haemost JTH. 2017;15:785-91.

25. Martino C, Gallone MS, Quarto M, et al. Immunization coverage among splenectomized patients: results of an ad hoc survey in Puglia region (south of Italy). Hum Vaccines Immunother. 2016;12:1277-9.

26. Wang J, Jones $\mathrm{P}$, Cheng $\mathrm{AC}$, et al. Adherence to infection prevention measures in a statewide spleen registry. Med J Aust. 2014;200:538-40.

27. Boam T, Sellars P, Isherwood J, et al. Adherence to vaccination guidelines post splenectomy: a five year follow up study. J Infect Public Health. 2017:10:803-8.

28. Kim HS, Kriegel G, Aronson MD. Improving the preventive Care of Asplenic Patients. Am J Med. 2012:125:454-6.

29. Mitchell AP, Boggan JC, Lau K, et al. Splenectomy as a destination: improving quality of care among Asplenic veterans through a travel clinic. Am J Med. 2017;130:856-61.

30. Lau D, Hu J, Majumdar SR, et al. Interventions to improve influenza and pneumococcal vaccination rates among community-dwelling adults: a systematic review and meta-analysis. Ann Fam Med. 2012;10:538-46.

31. Regan AK, Bloomfield L, Peters I, et al. Randomized controlled trial of text message reminders for increasing influenza vaccination. Ann Fam Med. 2017:15:507-14

32. Robson J, Boomla K, Hull SA. Progress in using the electronic health record to improve primary care. Br J Gen Pract. 2020;70:e215-20.

33. Arnott $A$, Jones $P$, Franklin $L$, et al. A registry for patients with Asplenia/ Hyposplenism reduces the risk of infections with encapsulated organisms. Clin Infect Dis Off Publ Infect Dis Soc Am. 2018;67:557-61.

34. O'Neal HR, Niven AS, Karam GH. Critical illness in patients with Asplenia. Chest. 2016;150:1394-402.

35. Spleen problems and spleen removal. nhs.uk. 2017. https://www.nhs.uk/ conditions/spleen-problems-and-spleen-removal/. Accessed 21 Aug 2019.

36. Hegarty PK, Tan B, O'Sullivan R, et al. Prevention of postsplenectomy sepsis: how much do patients know? Hematol J Off J Eur Haematol Assoc. 2000;1: $357-9$.

37. El-Alfy MS, El-Sayed MH. Overwhelming postsplenectomy infection: is quality of patient knowledge enough for prevention? Hematol J Off J Eur Haematol Assoc. 2004;5:77-80

38. Brigden ML, Pattullo A, Brown G. Pneumococcal vaccine administration associated with splenectomy: the need for improved education, documentation, and the use of a practical checklist. Am J Hematol. 2000;65:25-9.

39. Wald HS, George P, Reis SP, et al. Electronic health record training in undergraduate medical education: bridging theory to practice with curricula for empowering patient- and relationship-centered Care in the Computerized Setting. Acad Med. 2014;89:380-6.

40. Chaudhry B, Wang J, Wu S, et al. Systematic review: impact of health information technology on quality, efficiency, and costs of medical care. Ann Intern Med. 2006;144:742-52.

41. Downing MA, Omar AH, Sabri E, et al. Information on the internet for asplenic patients: a systematic review. Can J Surg J Can Chir. 2011:54:232-6.

42. Jansà M, Bertran MJ, Vilardell J, et al. Analysis of the quality of patient therapeutic education and information in a high complexity reference hospital. J Healthc Qual Res. 2018;33:343-51. 
43. Spleen Australia, https://spleen.org.au/VSR/Index.html. Accessed 16 May 2019

44. Public Health England. Promotional material on splenectomy: leaflet and card. 2015. https://www.gov.uk/government/publications/splenectomyleaflet-and-card, https://www.gov.uk/government/publications/ splenectomy-leaflet-and-card. Accessed 19 Aug 2019.

\section{Publisher's Note}

Springer Nature remains neutral with regard to jurisdictional claims in published maps and institutional affiliations.

Ready to submit your research? Choose BMC and benefit from:

- fast, convenient online submission

- thorough peer review by experienced researchers in your field

- rapid publication on acceptance

- support for research data, including large and complex data types

- gold Open Access which fosters wider collaboration and increased citations

- maximum visibility for your research: over $100 \mathrm{M}$ website views per year

At $B M C$, research is always in progress.

Learn more biomedcentral.com/submissions 